\title{
Become an agent of change
}

\author{
BY ALPHONSE CAREW, OD
}

W e tend to live as is life were static, each day similar to the next even though we know the old adage, "that the only thing constant in life is change" is true. Occasionally, we may plan on making things a little better just to get us by and for certain periods of time this may serve us well. However, anyone who is involved in a competitive business environment, like the eye care field, needs to learn the tools of anticipating change - being proactive and taking advantage of the opportunities that change always presents.

Whether in our personal or our professional life, both internal and external forces are always acting upon us and pushing us off of our comfortable path. Sometimes this is a simple nudge; and sometimes fate rears it's ugly head with a firm shove. If only a small number of variables change around us then the effect is somewhat linear and we can usually cope. But when many variables change at the same time and with great velocity then the change isn't linear anymore but resembles something like a hairball or steel wool. At this stage much effort will be needed to survive, let alone thrive, and unfortunately things can go from bad to worse in a hurried downward spiral.

We often feel uneasy about change because, for the most part, it is out of our control. The uncertainty of what may be coming added to the uncertainty of what to do when presented with the need to change can heighten our anxiety level. At some point the effort and time needed to face change can seem insurmountable and we fall further behind to the point where we give up. It's best to deal with changes early and often, and even better to predict them and act before they develop.

Eye care, like any business or professional activity, has seen dramatic changes over the last few decades and the pace of change will only accelerate in the near future. Technological advances, consolidation and intense competition to increase market share will continue at a much faster pace. Giants in the optical business, both inside and outside Canada, are poised to get closer to their intended consumer your patient. Large investments are being made to bring about vertical integration from the lens manufacturer through optical outlets directly to the consumer (again our patients). What role we will play in this massive infusion of investment remains to be seen, but perhaps it's best for you to consider your options, and think about a plan before this shows up next door to your practice.

Although many events will have at least some impact on you, you need identify the changes you have control over. Some changes may be significant, and have a true effect on us, but we have little, to no power over them. Events like the plight of child labour in Asia can impact us greatly, and we have strong feeling about them but unfortunately our opinion matters very little yet we spend an amazing amount of energy on them. Recognize these as the energy sinks they are.

At the opposite end there are changes which directly affect your personal or professional life and we can equally affect the change itself, spin it to our advantage, or ignore it at our peril. This is where you should spend most of your time and energy. Identify the changes that will have the greatest impact on you and your practice, and note the ones that you can leverage to your advantage.

Identifying changes that are important to you and those that you can manipulate, is the first step to lessening their impact and exploiting their opportunities. You 
need to be constantly scanning the horizon for what's happening in the eye care industry. Who's buying who? What new technologies are being introduced? Who are the new players in the industry? Who is failing? Journals, TV, magazines, newspaper, the web, conversations with colleagues and suppliers are just a few of the channels open to us to scan for changes that may ultimately affect us.

Once you have identified an area that needs your attention you need to decide how you are going to deal with it. Sometimes the choice can be as simple as avoidance, to get out of the way. Be careful, however, because often this is not the prudent choice and this quick fix may come back to bite you in the end. Avoidance really only works for matters that are irrelevant. Because change is unpredictable, you may have to look at many "what if" scenarios with various outcomes and actions and decide which is the best course of action, while understanding that at some point later you may need to change paths. But don't get caught up in "analysis paralysis" either. Decide on a course of action and change it later if needed. As the saying goes, "a good plan today is better than a perfect plan tomorrow".

The next step is to put your plan into action. This is the part where most people fall down. You need to take those first steps and gain inertia over change before it buries you. Often it seems like a crisis will ruin us but that's just a perception you can change. It's an opportunity to take another path. Go slowly if that is all that is required but don't be afraid to take a big risk if one is needed, for you "can't cross a chasm in two small jumps".

You will often need the help of others, especially for changes in your practice. You will need a clear sense direction and purpose. Communicate urgency to gain acceptance of your ideas from your partners and staff as well as enlist them in the action plan to make your practice stronger, to resist, and react to the challenges that are coming.

Become you own agent of change in your personal and professional life. Scan for changes and analyze the impact and opportunities these may have for you. Accept change as normal and typical, and don't fear its uncertainty, but embrace and act upon the opportunities it may present.
Visualizing Beyond Perceptions 2011 CES and OPTOFAIR

February 18 - 21, 2011

Pan Pacific Hotel and Vancouver Convention Centre

To Register: www.optometrists.bc.ca

<http://www.optometrists.bc.ca>

Early Bird Deadline is January 9, 2011

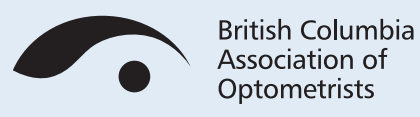

National Glaucoma Society National Cornea and Anterior Segment Society Continuing Education Programs

Marlborough, MA

Marlborough, MA

Orlando, FL

Falls Church, VA

Cape Cod, MA

November 7, 2010

December 5, 2010

January 16, 2011

March 20, 2011

July 23-25, 2011

Live Webinars available from all conferences

Conference Registration:

WWW.NECONFERENCES.COM

Toll-free: 877-825-2020 